\title{
THE REAL-WORLD COST AND EFFECTIVENESS STUDY OF TREATING mCRC WITH BEVACIZUMAB FOLLOWED BY CETUXIMAB OR PANITUMUMAB IN WT KRAS PATIENTS
}

\author{
IRENA SEHNALOVA $^{1}$, BARBORA RIHOVA $^{1} *$, RADIM NEMECEK ${ }^{2}$, KATERINA KINTROVA $^{3}$, \\ REGINA DEMLOVA ${ }^{1,2}$
}

${ }^{l}$ Department of Pharmacology, Faculty of Medicine, Masaryk University, Kamenice 5, 62500 Brno, Czech Republic

${ }^{2}$ Masaryk Memorial Cancer Institute, Zluty kopec 7, 65653 Brno, Czech Republic

${ }^{3}$ Department of Botany and Zoology, Faculty of Science, Masaryk University, Kotlarska 2, 61137 Brno, Czech Republic

*corresponding author: brihova@med.muni.cz

Manuscript received: May 2019

\begin{abstract}
Targeted monoclonal antibodies bevacizumab, cetuximab and panitumumab are reimbursed in the Czech Republic in combination with chemotherapy or alone in metastatic colorectal cancer (mCRC). However, the high cost is a potentially limiting factor. The real-world costs and effectiveness of first line bevacizumab followed by cetuximab or panitumumab (EGFRi) were retrospectively assessed from the perspective of healthcare payer. Total 71 WT KRAS patients (56\% men; median age 60.5 years) were evaluated between April 2007 and May 2017. During our follow-up period (30 months on average) 55\% patients died. The mean cost to PD was EUR 32,107 and EUR 24,510 in bevacizumab and EGFRi treatment respectively with median PFS 9.7 and 5.0 months. The median overall survival was 27.2 months and the mean cost from sequential therapy initiation to death was EUR 63,682 . The targeted therapy made up $77 \%, 86 \%$ and $76 \%$ of the costs in the first line, second line and from the initiation of sequential therapy to death respectively.
\end{abstract}

\section{Rezumat}

Anticorpii monoclonali bevacizumab, cetuximab și panitumumab sunt rambursați în Republica Cehă atât în monoterapie sau în combinație chimioterapice. $\mathrm{Cu}$ toate acestea, costul ridicat este un factor potențial limitativ. Costurile reale și eficacitatea bevacizumab, cetuximab și panitumumab (EGFRi) au fost evaluate în mod retrospectiv din perspectiva plătitorului de servicii medicale. 71 de pacienți KRAS KTT (56\% bărbați; vârsta medie 60,5 ani) au fost evaluați în perioada aprilie 2007 - mai 2017. În perioada de urmărire (în medie 30 de luni), 55\% dintre pacienți au murit. Costul mediu pentru progresia bolii a fost de 32.107 EUR și de 24.510 EUR în tratamentul cu bevacizumab și, respectiv, cu EGFRi. Supraviețuirea mediană totală a fost de 27,2 luni, iar costul mediu de la inițierea terapiei secvențiale până la deces a fost de 63.682 EUR. Terapia vizată a constituit $77 \%$, 86\% și 76\% din costurile aferente primei linii, celei de-a doua și respectiv de la inițierea terapiei secvențiale până la deces.

Keywords: bevacizumab, cetuximab, panitumumab, colorectal cancer, cost analysis

\section{Introduction}

Colorectal cancer (CRC) is the second most frequently diagnosed malignancy after prostate cancer in men and breast cancer in women in the Czech Republic. The most cases are reported in both men and women aged 65 - 69 years. The five-year relative survival rate among CRC patients reached about $58 \%$ for cases diagnosed between 2013 and 2016 [1]. Despite the ongoing national screening program, approximately $25 \%$ of new cases are diagnosed already in metastatic stage (mCRC) [7].

New agents, the anti-VEGF drugs (bevacizumab, aflibercept) which selectively bind to the human vascular endothelial growth factor and the anti EGFR drugs (cetuximab, panitumumab) which inhibit the epidermal growth factor receptor, have become a part of standard treatment of mCRC. In addition, an oral receptor tyrosine kinase inhibitor regorafenib was recently approved. Efficacy of all these drugs was confirmed by numerous randomised clinical trials (RCTs) [3, 4, $6,10,15]$

Patients who would previously have received traditional chemotherapy are now benefitting from targeted therapy, used alone or in conjunction with traditional chemotherapy. Because of the much higher costs of targeted therapies compared with conventional chemotherapy and the growing number of eligible patients (due to molecular subtyping) for individual agents, costs of targeted therapies as a group is an important contributor to growing expenditures for cancer treatments and an important issue of sustainability for all healthcare systems. All stakeholders - regulatory authorities, payers, industry, clinicians and patients need to communicate and develop strategies to enable access to effective (and 
cost-effective) targeted therapies without overspending the healthcare budget.

Current Czech health care system uses regulation tools in the pharmaceutical pricing and reimbursement process based on Act 48/1997. The pricing and reimbursement procedures are done by the State Institute for Drug Control, which is the main stakeholder in the decisionmaking process. Marketing authorization holders and insurance funds also participate in this process. The official price of every product is calculated as the mean of the three lowest prices within the European Union reference basket. For highly innovative drugs, a temporary reimbursement can be granted for a period of 3 years. During the administrative proceeding, efficacy, safety, cost-effectiveness, and budget impact are assessed [26]. Targeted drugs are allocated to the "S" symbol class; they may be therefore charged to the health insurer solely by comprehensive cancer centres under an agreement concluded with the health insurer.

The availability of the targeted therapy significantly increased the treatment costs in last fifteen years in the Czech Republic. The antineoplastic drugs make up almost $20 \%$ of the total drug consumption in financial terms and currently take the first place [8]. The data on clinical use and effectiveness of the targeted therapy in mCRC were collected using the clinical database called CORECT. The CORECT registry (http://corect.registry.cz) focuses on the collection of epidemiological and clinical data on mCRC patients treated with targeted therapies in the Czech Republic. The results were evaluated periodically and were mostly consistent with published RCTs. According to both national and European guidelines, patients with good performance status (ECOG 0-1) who progressed after targeted treatment, should be involved in another targeted therapy with different mechanism of action in the next line treatment $[2,28]$. Due to the high cost of the targeted therapy, the careful selection of patients who may benefit most from such treatment is of paramount importance. Moreover, these increasingly expensive medicines, which showed benefit to patients in randomized clinical trials, should demonstrate their position in the real-world clinical settings.

The aim of this real-world retrospective study was therefore to determine the direct medical cost and effectiveness (defined as progression-free survival and overall survival) of bevacizumab in the first line treatment followed by cetuximab or panitumumab in the second line treatment in mCRC patients with wild type Kirsten ras oncogene (WT KRAS).

\section{Materials and Methods}

The cost and effectiveness of targeted therapy in mCRC patients were retrospectively assessed between April
2007 and May 2017 in the comprehensive cancer centre in the Czech Republic from the perspective of healthcare payer. Cost data (examinations, medication, hospitalizations) were collected from the initiation of evaluated treatment to any tumour response (RECIST criteria - CR - complete response, PR - partial response, $\mathrm{SD}$ - stable disease, PD - disease progression) and/ or to death. The costs of clinical examination and procedures include laboratory tests, genetic testing for KRAS mutation, ambulatory visits, radiotherapy during and after discontinuation of targeted treatment, and examination methods like computer tomography, ultrasound and positron emission tomography. Discounting was not considered because analysis is based on real world data with relatively short followup of each patient. Costs were valued in CZK and converted to EUR $(1$ EUR $=26.23 \mathrm{CZK})$. The progression-free survival (PFS) was defined as the time from the targeted therapy initiation to the date of documented progression or death due to any cause. Overall survival (OS) was defined as the time from first line treatment initiation to the date of death due to any cause.

The Ethics Committee of the Masaryk Memorial Cancer Institute, Brno, Czech Republic, granted their approval to the data analyses.

Statistical analysis

Descriptive statistics were used to summarize all study variables. Categorical variables are summarized by the percentage of patients in each treatment category; continuous variables are summarized by the mean to enable comparison of results with other studies. Statistical analyses were calculated in R software. The costs and progression/survival data have mostly right skewed distribution therefore a square root transformation was used to reach a normal distribution before application of further statistical analyses. A regression analysis of linear models was used to test a hypothesis that there is no dependence between two examined variables, and the decision followed a result of the F-statistic. The Welch two sample t-test was used to test a hypothesis that two examined variables have equal means.

\section{Results and Discussion}

\section{Patients and effectiveness of $m C R C$ treatment}

A total of 71 WT KRAS patients with mCRC were treated with bevacizumab in the first line therapy and cetuximab or panitumumab subsequently in the second line therapy between April 2007 and May 2017 in National Comprehensive Cancer Centre in the Czech Republic. There were 40 men $(56 \%$, median age 60.5 years) and 31 women (44\%, median age 60 years). Sixty-five patients were evaluated in the first line therapy. Six patients of 71 were excluded due to a missing date of the first line therapy completion. In the second line therapy, 51 patients were followed, 
as 20 patients were excluded due to participation in a clinical trial, i.e. under different patient examination protocol and reimbursement conditions. Total 39 patients died within the monitored period. Average follow-up in our study was 30 months.

Bevacizumab in the first line treatment

In the first line therapy, there were 35 men (54\%, median age 60 years) and 30 women (46\%, median age 60.5 years) analysed (Table I). The median progression free survival (PFS) on bevacizumab therapy was 9.7 months which is comparable to previous randomised study where median PFS in a group treated with XELOX or FOLFOX with bevacizumab was 9.4 months [23]. A slightly higher effectiveness (median PFS 10.1 months) was observed in a retrospective observational study which evaluated the cost-effectiveness of the addition of bevacizumab to the regimen with irinotecan-fluorouracil in the first line treatment [22].
Women left the first-line therapy earlier than men did (median 7.6 and 11.0 months, respectively; p-value 0.045 and $t_{61.8}=2.049$ ), but the significant difference is not considered as clinically relevant. The regression analysis did not prove any dependence between the progression free survival and age of patients $\left(\mathrm{F}_{1.63}=\right.$ $0.31, \mathrm{p}=0.58)$. Disease progression was the most frequent reason for the first line treatment discontinuation (Table I). All patients underwent chemotherapy; seven patients $(11 \%)$ underwent radiotherapy for metastases. The most common chemotherapy regimen was XELOX in $62 \%$ patients followed by FOLFOX in $18 \%$ of patients (Table II). Bevacizumab treatment was not terminated by surgery in any of our patients. WT KRAS status and good performance status (ECOG 0-1) was the reason for EGFRi administration in the second line treatment.

Table I

Baseline patient characteristics

\begin{tabular}{|c|c|c|c|}
\hline & $\begin{array}{c}\text { First line bevacizumab } \\
\text { (total 65) } \\
\mathrm{N}(\%) \\
\end{array}$ & $\begin{array}{l}\text { Second line EGFRi } \\
\text { (total 51) } \\
\mathrm{N}(\%) \\
\end{array}$ & $\begin{array}{l}\text { From the first line initiation to death } \\
\text { (total 39) } \\
\mathrm{N}(\%)\end{array}$ \\
\hline \multicolumn{4}{|l|}{ Gender } \\
\hline male & $35(54)$ & $29(57)$ & $21(54)$ \\
\hline female & $30(46)$ & $22(43)$ & $18(46)$ \\
\hline \multicolumn{4}{|l|}{ Median age } \\
\hline male & 60 & 61 & 60 \\
\hline female & 60,5 & 61,5 & 61,5 \\
\hline \multicolumn{4}{|l|}{ Reasons for discontinuation } \\
\hline disease progression & $56(86)$ & $43(84)$ & - \\
\hline adverse events & $6(9)$ & $3(6)$ & - \\
\hline other reasons* & $3(5)$ & $4(8)$ & - \\
\hline complete response & - & $1(2)$ & - \\
\hline
\end{tabular}

* Other reasons include rejection of treatment continuation and other reasons without exact specification.

Table II

Chemotherapy regimens in the first line treatment $(\mathrm{N}=65)$

\begin{tabular}{lcc}
\multicolumn{1}{c}{ Regimen* } & No. of patients & $\%$ of patients \\
\hline Bev+XELOX & 40 & $62 \%$ \\
\hline Bev+FOLFOX & 12 & $18 \%$ \\
\hline Bev+XELIRI & 4 & $6 \%$ \\
\hline Bev+FOLFIRI & 3 & $5 \%$ \\
\hline Bev+bFOL & 4 & $6 \%$ \\
\hline Bev+FUFA & 2 & $3 \%$
\end{tabular}

* XELOX - capecitabine,oxaliplatin; FOLFOX - leucovorin, 5fluorouracil, oxaliplatin; XELIRI - capecitabine, irinotecan; FOLFIRI - leucovorin, 5-fluorouracil, irinotecan; bFOL - leucovorin, 5-fluorouracil bolus, oxaliplatin; FUFA - leucovorin, 5-fluorouracil.

\section{EGFRi in the second line treatment}

Fifty-one patients were evaluated in the second line treatment with EGFRi (cetuximab 41 patients, $80 \%$ and panitumumab 10 patients, 20\%). Total 46 patients underwent the treatment with EGFRi and irinotecan, 5 patients underwent the treatment with EGFRi in monotherapy. The disease progression was the most common reason for treatment discontinuation (Table
I); the median PFS on EGFRi was 5.0 months which is slightly favourable for our study population. Previous results of ASPECCT study showed median PFS 4.4 months and 4.2 months in patients treated with cetuximab and panitumumab, respectively [21]. Complete response followed by surgery was recorded in one patient. Although, recent data from the real clinical practice suggest that patients treated with bevacizumab before EGFRi had a poorer PFS on EGFRi therapy compared to patients without a previous bevacizumab therapy [5], the real-world outcomes on patient-level population in our analysis confirmed longer PFS in sequential therapy compared to RCT. The age of patients had no influence on the therapy duration $\left(\mathrm{F}_{1.49}=0.99, \mathrm{p}=\right.$ 0.32).

Sequential therapy from the first line treatment to death

Thirty-nine patients who died during our follow-up period were analysed in the sequential therapy of bevacizumab followed by EGFRi. After discontinuation of the second line treatment with EGFRi four patients were treated with regorafenib in the third or fourth line treatment. Two patients (5\%) underwent palliative 
radiotherapy after discontinuation of targeted therapy. The median overall survival (OS) was 27.2 months. Kaplan-Meier curve has been created for estimation of survival probability of patient's population (Figure 1).

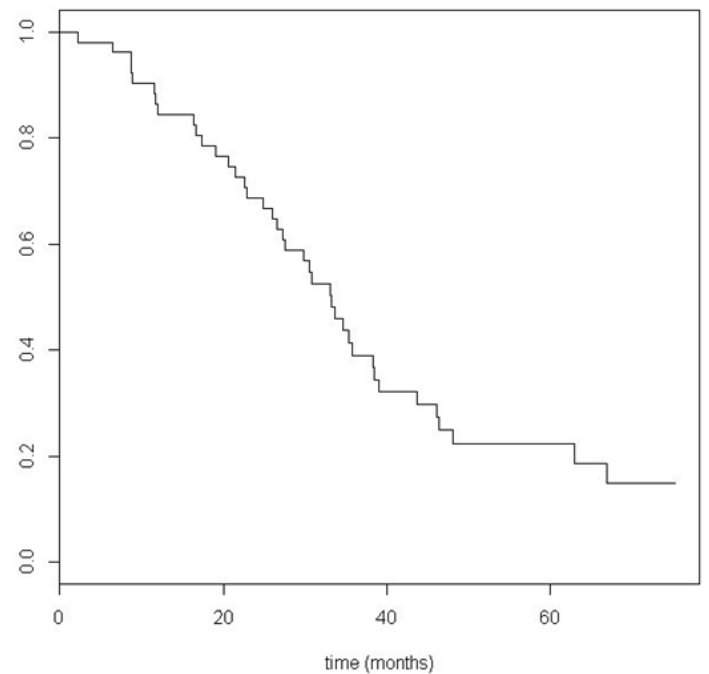

Figure 1.

Kaplan-Meier curve of survival probability of patient's population

Costs of mCRC treatment

Bevacizumab in the first line treatment. The mean total cost of treatment in the first line therapy was EUR 32,107 per patient, mean monthly cost was EUR 3,034 . The highest percent of the costs was spent on bevacizumab; $77 \%$ of the total costs to first PD (EUR 24,789/patient); Table III, Figure 2.

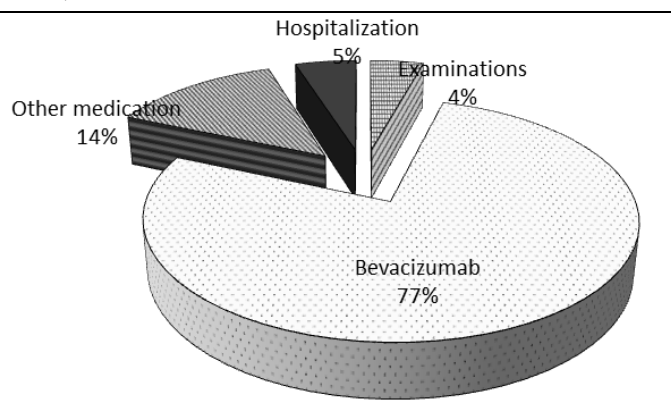

Figure 2.

The structure of costs in bevacizumab first line treatment

EGFRi in the second line treatment. The total mean costs of treatment irrespective of the drug agent (cetuximab or panitumumab) were EUR 24,510 in the second line therapy. The mean monthly cost was EUR 4,889; cetuximab EUR 4,795 and panitumumab EUR 5,276, respectively. The evaluated drugs formed $86 \%$ (EUR 20,994/patient) of total costs; Table III, Figure 3.

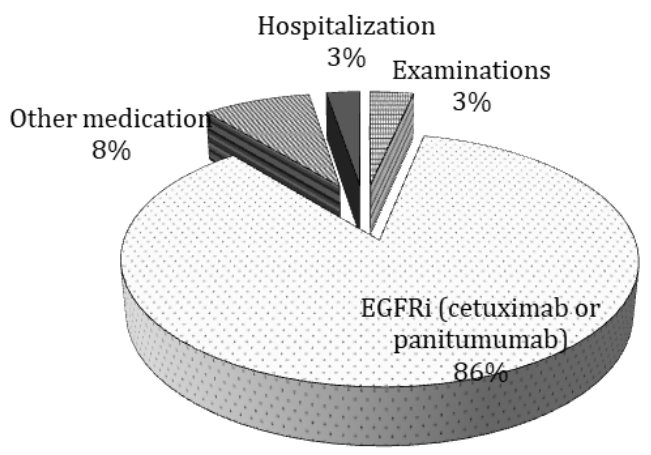

Figure 3.

The structure of costs in EGFRi second line treatment

Table III

The treatment outcomes and health care costs (EUR) according to the treatment line First line bevacizumab Second line EGFRi From the first line initiation to death $(\mathrm{N}=65)$ $(\mathrm{N}=51)$ $(\mathrm{N}=39)$

\begin{tabular}{|c|c|c|c|}
\hline \multicolumn{4}{|l|}{ Treatment outcomes } \\
\hline PFS* (months) & 9.7 & 5.0 & \\
\hline OS* (months) & & & 27.2 \\
\hline \multicolumn{4}{|l|}{ Mean costs (EUR) } \\
\hline Targeted drugs & 24,789 & 20,994 & 48,582 \\
\hline Other medications & 4,368 & 2,048 & 9,645 \\
\hline Examinations & 1,369 & 829 & 3,185 \\
\hline Hospitalizations & 1,582 & 639 & 2,270 \\
\hline Total & 32,107 & 24,510 & 63,682 \\
\hline
\end{tabular}

* PFS - progression-free survival; OS - overall survival

Cost of sequential therapy from the first line treatment to death

The mean cost of sequential therapy from the initiation of first line treatment to death was EUR 63,682; mean monthly cost was EUR 2,344. The cost of targeted therapy (bevacizumab, EGFRi and regorafenib) made up $76 \%$ (EUR 48,582/patient), other medications $15 \%$ (EUR 9,645/patient), examinations 5\% (EUR 3,185/ patient) and hospitalizations 4\% (EUR 2,270/patient) of total costs; Table III.

Our cost analysis confirms high proportion of costs spent on targeted therapy and these findings are consistent with previous research in the Czech Republic [14, 20]. During the pricing and reimbursement procedure, the cost effectiveness analysis of targeted agents is assessed, but the calculation of costs and effectiveness is not based on patient-level data. It is essential to 
verify the cost-effectiveness in the real-world clinical settings. Although systems of pricing and reimbursement vary significantly, high cost of targeted therapy is a worldwide issue. The study of real-world direct health care costs in mCRC patients in the United States showed that the average cost of cancer regimen per month was USD 13,646 if bevacizumab in the first line and cetuximab in the second line had been administered, which presented $60 \%$ of the total costs. Similarly, the average cost per month was USD 12,773 if bevacizumab in the first line and panitumumab in the second line had been used [18]. However, direct costs in the Czech Republic and USA are not comparable due to different socioeconomic status and distinctions in a way of reimbursement of health care.

European cost data could be more comparable due to the similarities in health care systems and size of the economies. For instance, Portuguese cost study calculated the cost EUR 2,057 per month with bevacizumab in the first line treatment [25] which correspond to our study - the average cost of bevacizumab was about EUR 2,500. In the Finish cost study of CRC the total direct medical costs were approximately EUR 2,380 per month [9]. These findings correlate to our results where average total costs from initiation of targeted treatment to death generated approximately EUR 2,344 per patient and month.

Our study has been focused on WT KRAS patients with $\mathrm{mCRC}$ who underwent the sequential therapy with bevacizumab in the first line and EGFRi (cetuximab or panitumumab) in the second line treatment in the real-world clinical practice in the Czech Republic. According to ESMO (European Society for Medical Oncology) guidelines for the management of patients with $\mathrm{mCRC}$, the patients with RAS wild-type disease who received bevacizumab in the first line should be considered for treatment with EGFRi in combination with FOLFIRI or irinotecan $[14,28]$. Currently, median OS in patients with mCRC is approximately 30 months which is almost three times compared to the era before targeted drugs [12]. However, the increased use of targeted therapies and the ever-rising drug costs make the current system unsustainable. Increased costs due to the administration of bevacizumab, cetuximab and panitumumab in mCRC treatment were published in recent years $[11,13,17,22]$. The analysis of medical cost associated with the treatment of CRC in the USA indicated that the average annualized cost for patients with metastasis was nearly twice as big as for those without metastasis [24]. Given that the medication costs account for the major part of total expenses in the Czech Republic, the key issue remains to be the selection of patients with highest expected benefit from the targeted therapy. Mutations of RAS oncogene were identified as a predictive marker in $\mathrm{mCRC}$ and the confirmed WT RAS oncogene is necessary for initiation of cetuximab and panitumumab administration.
The testing of RAS oncogene before initiation of EGFR inhibitors treatment was proven to be costeffective [19] and became a standard examination routine in the Czech Republic. The cost of KRAS mutation examination is EUR 219 per patient. This cost is included in the costs of examination in the first line treatment (before EGFRi treatment initiation) in our analysis. Nevertheless, there is no clinical biomarker currently available for bevacizumab administration [27]. The additional analysis of bevacizumab clinical benefit relative to KRAS mutation status confirmed independence on KRAS mutation [16].

Limitations

The main limitation of our study is a relatively small group of patients treated in one comprehensive cancer centre and the possible underestimation of end-of-life costs in selected patients who were treated in another hospital. However, most patients remain in care at one cancer clinic even after the termination of targeted therapy. Another limiting factor is the lack of data on other co-morbidities, but good performance status (ECOG 0-1) is required to initiate targeted treatment, which excludes serious co-morbidities that would significantly increase costs. Due to the later approval of reimbursement of panitumumab and hence less experience with it in the Czech Republic, we have more patients treated with cetuximab in the second line treatment ( $20 \%$ vs. $80 \%$ of patients).

\section{Conclusions}

The cost of the targeted therapy was a major cost driver in our analysis and confirmed analogous structure to other pharmacoeconomic studies suggesting transferability of our findings despite a relatively small study population. The cost of bevacizumab in the first line treatment of mCRC was EUR 24,789 per patient and formed $77 \%$ of the total cost until disease progression. Similarly, the costs of EGFR inhibitors in the second line treatment of mCRC were EUR 20,994 per patient and made up $86 \%$ of the total costs until the second disease progression on targeted therapy. The average total costs since the initiation of the first line treatment to death were EUR 63,682 per patient, of which the targeted drugs made up 76\% (EUR 48,582/patient). The effectiveness of targeted treatment corresponded to the efficacy published in previous clinical trials, median PFS 5.0 months achieved in the second line treatment with EGFRi is slightly favourable for our study population in comparison with published clinical trials.

The issue of expenditure on targeted treatment remains a topic between regulatory authorities, heath care payers, the clinical community, the patients and the public. Regulatory authorities in individual countries re-evaluate the benefit of targeted drugs according to the outcomes in the real-world clinical practice not only in oncology but also in the treatment of other 
diseases where these new expensive drugs are used. Based on current evidence, the other prospective studies on patient-level data could help to evaluate clinical outcomes and to reassess cost-effectiveness of the targeted therapy in the real-world clinical practice. The careful selection of patients who may benefit most from such treatment remains a key issue, which could help to reduce the impact of high cost of targeted agents in the health care system. Our results which present the real-world data can be also used for prediction of future costs spent on mCRC.

\section{Acknowledgement}

Supported by the state budget by the MEYS, large infrastructure project CZECRIN (No. LM2015090) and European Regional Development Fund - Project CZECRIN_4 PACIENTY (No. CZ.02.1.01/0.0/0.0/16_ 013/0001826).

\section{Conflict of interest}

The authors declare no conflict of interest.

\section{References}

1. Cancer incidence, Institute of Health Information and Statistics of the Czech Republic, http://uzis.cz/en/ catalogue/cancer-incidence

2. Van Cutsem E, Cervantes A, Adam R, Sobrero A, Van Krieken JH, Aderka D, Aranda Aguilar E, Bardelli A, Benson A, Bodoky G, Ciardiello F, D'Hoore A, Diaz-Rubio E, Douillard JY, Ducreux M, Falcone A, Grothey A, Gruenberger T, Haustermans K, Heinemann V, Hoff P, Köhne CH, Labianca R, LaurentPuig P, Ma B, Maughan T, Muro K, Normanno N, Österlund P, Oyen WJ, Papamichael D, Pentheroudakis G, Pfeiffer P, Price TJ, Punt C, Ricke J, Roth A, Salazar R, Scheithauer W, Schmoll HJ, Tabernero J, Taïeb J, Tejpar S, Wasan H, Yoshino T, Zaanan A, Arnold D, ESMO consensus guidelines for the management of patients with metastatic colorectal cancer. Ann Oncol., 2016; 27(8): 1386-422.

3. Van Cutsem E, Köhne CH, Láng I, Folprecht G, Nowacki MP, Cascinu S, Shchepotin I, Maurel J, Cunningham D, Tejpar S, Schlichting M, Zubel A, Celik I, Rougier P, Ciardiello F, Cetuximab Plus Irinotecan, Fluorouracil, and Leucovorin As FirstLine Treatment for Metastatic Colorectal Cancer: Updated Analysis of Overall Survival According to Tumor KRAS and BRAF Mutation Status. J Clin Oncol., 2011; 29(15): 2011-2019.

4. Van Cutsem E, Tabernero J, Lakomy R, Prenen H, Prausová J, Macarulla T, Ruff P, van Hazel GA, Moiseyenko V, Ferry D, McKendrick J, Polikoff J, Tellier A, Castan R, Allegra C, Addition of Aflibercept to Fluorouracil, Leucovorin, and Irinotecan Improves Survival in a Phase III Randomized Trial in Patients With Metastatic Colorectal Cancer Previously Treated With an Oxaliplatin-Based Regimen. J Clin Oncol., 2012; 30(28): 3499-3506.

5. Derangère $\mathrm{V}$, Fumet JD, Boidot $\mathrm{R}$, Bengrine $\mathrm{L}$, Limagne E, Chevriaux A, Vincent J, Ladoire S, Apetoh
L, Rébé C, Ghiringhelli F, Does bevacizumab impact anti-EGFR therapy efficacy in metastatic colorectal cancer?. Oncotarget, 2016; 7(8): 9309-9321.

6. Douillard JY, Siena S, Cassidy J, Tabernero J, Burkes R, Barugel M, Humblet Y, Bodoky G, Cunningham D, Jassem J, Rivera F, Kocákova I, Ruff P, BłasińskaMorawiec M, Šmakal M, Canon JL, Rother M, Oliner KS, Wolf M, Gansert J, Randomized, Phase III Trial of Panitumumab With Infusional Fluorouracil, Leucovorin, and Oxaliplatin (FOLFOX4) Versus FOLFOX4 Alone As First-Line Treatment in Patients With Previously Untreated Metastatic Colorectal Cancer: The PRIME Study. J Clin Oncol., 2010; 28(31): 4697-4705.

7. Dusek L, Muzik J, Kubasek M, Koptikova J, Zaloudik J, Vyzula R, Epidemiology of Malignant Tumours in the Czech Republic. Version 7.0. Masaryk University, Czech Republic. www.svod.cz

8. Economic information on health care, Institute of Health Information and Statistics of the Czech Republic. http://uzis.cz/en/catalogue/economicinformation-health-care

9. Färkkilä N, Torvinen S, Sintonen H, Saarto T, Järvinen H, Hänninen J, Taari K, Roine RP, Costs of colorectal cancer in different states of the disease. Acta Oncol., 2015; 54(4): 454-462.

10. Grothey A, Van Cutsem E, Sobrero A, Siena S, Falcone A, Ychou M, Humblet Y, Bouché O, Mineur L, Barone C, Adenis A, Tabernero J, Yoshino T, Lenz HJ, Goldberg RM, Sargent DJ, Cihon F, Cupit L, Wagner A, Laurent D, Regorafenib monotherapy for previously treated metastatic colorectal cancer (CORRECT): an international, multicentre, randomised, placebocontrolled, phase 3 trial. The Lancet, 2013; 381(9863): 303-312.

11. Hedden L, Kennecke H, Villa D, Johnston K, Speers C, Kovacic L, Renouf DJ, Peacock S, Incremental cost-effectiveness of the pre- and post-bevacizumab eras of metastatic colorectal cancer therapy in British Columbia, Canada. Eur J Cancer, 2012; 48(13): 1969-1976.

12. Heinemann V, Douillard JY, Ducreux M, Peeters M, Targeted therapy in metastatic colorectal cancer An example of personalised medicine in action. Cancer Treat Rev., 2013; 39(6): 592-601.

13. Hoyle M, Crathorne L, Peters J, Jones-Hughes T, Cooper C, Napier M, Tappenden P, Hyde C, The clinical effectiveness and cost-effectiveness of cetuximab (mono- or combination chemotherapy), bevacizumab (combination with non-oxaliplatin chemotherapy) and panitumumab (monotherapy) for the treatment of metastatic colorectal cancer after first-line chemotherapy (review of technology appraisal No.150 and part review of technology appraisal No. 118): a systematic review and economic model. Health Technol Assess Winch Engl., 2013; 17(14): 1-237.

14. Hradecka I, Rihova B, Horova R, Demlova R, The cost study of first-line treatment of metastatic colorectal carcinoma with bevacizumab-containing regimen in the Czech Republic. Klin Onkol., 2014; 27(4): 255-260.

15. Hurwitz H, Fehrenbacher L, Novotny W, Cartwright T, Hainsworth J, Heim W, Berlin J, Baron A, Griffing S, 
Holmgren E, Ferrara N, Fyfe G, Rogers B, Ross R, Kabbinavar F, Bevacizumab plus Irinotecan, Fluorouracil, and Leucovorin for Metastatic Colorectal Cancer. $N$ Engl J Med., 2004; 350(23): 2335-2342.

16. Hurwitz HI, Yi J, Ince W, Novotny WF, Rosen O, The clinical benefit of bevacizumab in metastatic colorectal cancer is independent of K-ras mutation status: analysis of a phase III study of bevacizumab with chemotherapy in previously untreated metastatic colorectal cancer. The Oncologist, 2009; 14(1): 22-28.

17. Huxley N, Crathorne L, Varley-Campbell J, Tikhonova I, Snowsill T, Briscoe S, Peters J, Bond M, Napier M, Hoyle M, The clinical effectiveness and costeffectiveness of cetuximab (review of technology appraisal no. 176) and panitumumab (partial review of technology appraisal no. 240) for previously untreated metastatic colorectal cancer: a systematic review and economic evaluation. Health Technol Assess Winch Engl., 2017; 21(38): 1-294.

18. Johnston $\mathrm{S}$, Wilson $\mathrm{K}$, Varker H, Malangone-Monaco E, Juneau P, Riehle E, Satram-Hoang S, Sommer N, Ogale S, Real-world Direct Health Care Costs for Metastatic Colorectal Cancer Patients Treated With Cetuximab or Bevacizumab-containing Regimens in First-line or First-line Through Second-line Therapy. Clin Colorectal Cancer, 2017; 16(4): 386-396.

19. Kircher SM, Mohindra N, Nimeiri H, Cost Estimates and Economic Implications of Expanded RAS Testing in Metastatic Colorectal Cancer. The Oncologist, 2015; 20(1): 14-18.

20. Ondrackova B, Demlova R, Kominek J, Economic evaluation of targeted biologic therapy in metastatic renal cell carcinoma. Klin Onkol., 2010; 23(6): 439-445.

21. Price T, Kim TW, Li J, Cascinu S, Ruff P, Suresh AS, Thomas A, Tjulandin S, Guan X, Peeters M, Final results and outcomes by prior bevacizumab exposure, skin toxicity, and hypomagnesaemia from ASPECCT: randomized phase 3 non-inferiority study of panitumumab versus cetuximab in chemorefractory wild-type KRAS exon 2 metastatic colorectal cancer. Eur J Cancer., 2016; 68(Supplement C): 51-59.

22. Ruiz-Millo O, Albert-Mari A, Sendra-Garcia A, Jimenez-Torres NV, Comparative cost-effectiveness of bevacizumab-irinotecan-fluorouracil versus irinotecanfluorouracil in first-line metastatic colorectal cancer. J Oncol Pharm Pract., 2014; 20(5): 341-350.

23. Saltz LB, Clarke S, Díaz-Rubio E, Scheithauer W, Figer A, Wong R, Koski S, Lichinitser M, Yang TS, Rivera F, Couture F, Sirzén F, Cassidy J, Bevacizumab in Combination With Oxaliplatin-Based Chemotherapy As First-Line Therapy in Metastatic Colorectal Cancer: A Randomized Phase III Study. J Clin Oncol., 2008; 26(12): 2013-2019.

24. Seal BS, Sullivan SD, Ramsey S, Shermock KM, Ren J, Kreilick C, Foltz Boklage SH, Valluri S, Sarma S, Asche CV, Medical Costs Associated with Use of Systemic Therapy in Adults with Colorectal Cancer. J Manag Care Pharm., 2013; 19(6): 461-467.

25. Silva C, Monteiro I, Tournier C, Bevacizumab in The Treatment of Kras Wild Type Metastatic Colorectal Cancer: An Economic Analysis Based on The Calgb 80405 Trial. Value Health, 2016; 19(7): A723.

26. Skoupa J, Drug Policy in the Czech Republic. Value Health Reg Issues, 2017; 13: 55-58.

27. Varol U, Yildiz I, Salman T, Karabulut B, Uslu R, Markers to predict the efficacy of bevacizumab in the treatment of metastatic colorectal cancer. Tumori, 2014; 100(4): 370-376.

28. Vyzula R, Modra kniha. Czech Society for Oncology. [The Blue book of the Czech Society for Oncology]. www.linkos.cz/informace-pro-praxi/modra-kniha/ 